Vol. 11, No. 38, January, 2016, 193-202

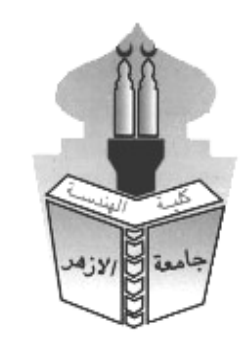

\title{
USING ROAD TEST FOR INSPECTION OF AN AUTOMOTIVE ENGINE
}

\author{
Adham Mohamed Abdelkader. \\ Automotive Engineering Department ASU
}

\begin{abstract}
The engine power could be measured accurately using an engine dynamometer but this process is time and money consuming due to difficulty of coupling the engine to the dynamometer. The coupling process can be eliminated using chassis dynamometer. Hence the chassis dynamometer is a road resistance simulator. Why not to take the actual road as the source of resistance instead of using chassis dynamometer? This process will be faster and cheaper taking less than a minute on road for a single test and will help to detect the condition of the engine and power train easily.

The aim of this paper is to evaluate the use of the road as a source of resistance for the calculation of engine power. Nowadays, there are many software products that claim the possibility to measure the engine power on road.

In our study road tests have been performed using OBD (On Board Diagnostic System) reader devices and high-speed GPS (Global Positioning System) receiver to measure vehicle speed variation with time during acceleration process. Three different vehicles are used to validate the road tests obtained data using chassis dynamometer. The proposed method proved its ability of using road test during automotive engine inspection process. Based on the validation the OBD and GPS data shows a difference between both methods by $\pm 2 \%$.
\end{abstract}

\section{INTRODUCTION:}

The process of measuring engine power could be performed on engine dynamometer after dismantling the engine from the vehicle. But this process is not economical and not reasonable for routine determination of the condition of the engine on the other hand using chassis dynamometer for such inspection. In the second method, previous studies described the calculation of engine power by assuming power train efficiency. The value of power train efficiency is the product of transmission efficiency and final reduction (differential) efficiency.

J. Hromádko et al [1] presented that the process of measuring the engine power could be performed by two ways using steady state method or modern acceleration method under no load. They concluded that the steady state test method gave more accurate results. The acceleration method accuracy was improved at no load when inertia flywheel was added.

M. Pexa et al [2] presented the option of using GPS receiver to determine the torque of the engine and its backup torque seemed to be an appropriate option. The compression between measured curve using GPS and engine dynamometer is shown in figure 1. They thus concluded that GPS data thus collected would contribute to detection of engine defects. Monitoring the progress of engine parameters (torque and engine power) is possible mainly by dynamometer, which is not affordable for common use. 


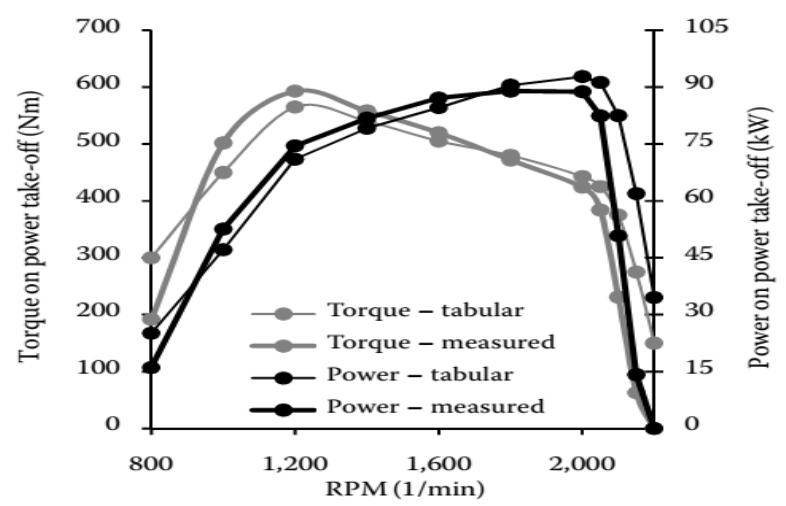

Fig. 1. Fendt Farmer 412 Vario power parameters determined by M. Pexa et al [2]

There are different programs that can be installed on PC(such as SCANXL 3and Dyno Scan) or even smart phones (such as Dynomaster, and OBD 2 Dyno+Diagnostics) that clam the ability to measure engine power. All programs adopt the idea of using the acceleration test method to calculate engine power, but they differ in the source of data by which they record the engine parameters. Some of the programs record the engine speed and vehicle speed using the OBDII reader, others use the built in or external GPS to record the vehicle speed. The error of the obtained data from these programs is reported to be 10-20\% from the actual engine performance characteristics. This rises the need to define whether or not the on road acceleration power measurement method can be used to inspecting the automotive engine power for fault diagnoses and maintenance.

\section{Road resistances}

This part is directed to evaluating the calculation of the engine power using acceleration method. The source of power is the engine and its relation to the available wheels power can be calculated as follows in equation 1:

$$
\mathrm{P}_{\text {wheels }}=\eta_{\text {trans }} \eta_{\text {fr }} \mathrm{P}_{\mathrm{e}}
$$

Where $\mathrm{P}$ wheels and $\mathrm{P}_{\mathrm{e}}$ are the wheels power and the engine power respectively $(\mathrm{kW})$, $\eta_{\text {trans }}$ is the transmission efficiency and $\eta_{\mathrm{fr}}$ is the final reduction ratio efficiency. The value of $\eta_{\text {trans }}$ was studied in SAE J2453[4] and is found to vary from 0.93 to 0.98 . The final reduction ratio efficiency $\eta_{\mathrm{Fr}}$ was presented in Bosch handbook 5] and by J.Y. Wong [6] is found to vary from 0.93 to 0.95 .

So by substituting in equation 1 and rewriting

$\mathrm{P}_{\mathrm{e}}=\mathrm{P}_{\text {wheels }} /[0.864-0.931]$

So in order to calculate the engine power it is required to accurately measure $\mathrm{P}_{\text {wheels }}$. Generally power equals to force times velocity:

$$
\mathrm{P}_{\text {wheels }}=\mathrm{F}_{\text {wheels }} . \mathrm{V}_{\text {wheels }}
$$

Where $F_{\text {wheels }}$ is the forces on wheels in the direction of motion $(\mathrm{N}), \mathrm{V}_{\text {wheels }}$ is the linear velocity of the vehicle $(\mathrm{m} / \mathrm{s}) . \mathrm{F}_{\text {wheels }}$ which is the sum of the resisting forces $(\mathrm{N})$; air resistance, rolling resistance, gradient resistance and inertia force J.Y. Wong [6].

$$
\mathrm{F}_{\text {wheels }}=\mathrm{F}_{\mathrm{ar}}+\mathrm{F}_{\mathrm{rr}}+\mathrm{F}_{\mathrm{gr}}+\mathrm{F}_{\mathrm{i}}
$$

Where $F_{a r}$ is the air resistance force, $F_{r r}$ is the rolling resistance force, $F_{g r}$ is the gradient resistance force and $F_{i}$ is inertia force. 


$$
\mathrm{F}_{\mathrm{ar}}=0.5 \rho \mathrm{C}_{\mathrm{D}} \mathrm{A} \mathrm{V}^{2}
$$

Where $\rho$ is the air density $\left(\mathrm{m}^{3} / \mathrm{kg}\right), \mathrm{C}_{\mathrm{D}}$ is the drag coefficient, $\mathrm{V}$ is the vehicle speed $(\mathrm{m} / \mathrm{s})$ and $A$ is the frontal area of the vehicle $\left(\mathrm{m}^{2}\right)$ which can be calculated as from SAE J1349 as follows:

$$
\mathrm{A}=0.8 \mathrm{~W} \mathrm{H}
$$

Where $\mathrm{W}$ is the width of the vehicle without mirrors and $\mathrm{H}$ is the height of the vehicle in $(\mathrm{m})$

$$
\text { Rolling resistance }=\mathrm{F}_{\mathrm{rr}} \mathrm{W}
$$

Where $\mathrm{F}_{\mathrm{rr}}$ is the rolling resistance coefficient and $\mathrm{W}_{\mathrm{g}}$ is the vehicle weight $\mathrm{N}$.

$$
\mathrm{F}_{\mathrm{gr}}=\mathrm{W}_{\mathrm{g}} \sin \theta
$$

Where $\theta$ is the road gradient. Gradient resistance could be neglected on level road.

Inertia force from Newton's law

Inertia force $=$ linear inertia force + rotational inertia force

From Newton's Second Law:

$$
\text { Linear inertia force }=\mathrm{m} \text { a }
$$

Where $\mathrm{m}$ is the mass of the vehicle $(\mathrm{kg})$ and $\mathrm{a}$ is the acceleration of the vehicle $\left(\mathrm{m} / \mathrm{s}^{2}\right)$. Rotational parts have resisting inertia effect that should be taken based on J.Y. Wong [6]. Neglecting of rotational parts inertia led to reduced accuracy by J. Hromádko et al [1] and [3] when testing engine power. J.Y. Wong [6] formulated the rotating parts effect as follows:

$$
\mathrm{RE}=1.04+0.0025 \gamma^{2}
$$

Where RE is the rotating parts effect and $\gamma$ is the total reduction ratio so if the wheel power is calculated the engine power is equal to rotating parts effect multiply by wheel power and by total efficiency

Pe $=$ RE.P wheels $/ \eta_{\text {trans }} \cdot \eta_{\text {Fr }}$

H.B. Pacejka[8] studied the combination of modeling longitudinal and lateral tire's slip and presented Magic Formula which is widely used in tires slip calculations. So in order to overcome the calculation of slip actual vehicle speed is measured using GPS. This leads to the possibility of measuring engine power on road.

\section{Experimental Work:}

The main target from experimental work is to find whether is it possible to calculate the engine power from on road tests or not? Based on the previous calculations it is required to measure the instant actual vehicle velocity accurately to overcome the problem of tires' slip. A high speed GPS QSTARZ BT-Q818XT (with sample rate 10 $\mathrm{Hz}$ ) is used in order to measure the vehicle speed (with resolution of $0.01 \mathrm{~km} / \mathrm{hr}$ ) in addition to a recording device a smart phone with software Racechrono[9]. The data is extracted from the smart phone and then engine power is calculated. The engine speed and vehicle speed are also recoded simultaneously using OBDII reader and software (OBD 2 Dyno+Diagnostics) on another smart phone. The ambient conditions is taken into consideration for correcting the engine power according to SAE J1349 [7]. Coast down test is performed in order to calculate drag coefficient and rolling resistance coefficient to be used in engine power calculation.

Comparative Tests have been performed on three different passenger cars. Laboratory steady state power tests are performed on the same vehicles used by chassis dynamometer in order to check the agreement of on road test with the chassis dynamometer test.

1- LADA 2107 (specifications are in appendix A) is tested using GPS for road test and results are compared with chassis dynamometer test results. 
2- Hyundai Verna (specifications are in appendix B) is tested using both GPS and OBD reader for road test and results are compared with chassis dynamometer test results.

3- Renault Logan (specifications are in appendix C) fitted with automatic transmission is is tested using both GPS and OBD reader for road test and results are compared with chassis dynamometer test results.

\section{EQUIPMENT}

Equipment used can be classified into two types: equipment used in testing in the laboratory and equipment used for road tests. The main laboratory equipment is the chassis dynamometer which is used to measure the wheel power and hence to calculate the engine power.

1-The chassis dynamometer is roller type fitted with water cooled eddy current dynamometer to absorb the energy generated by the engine shown in figure 2 . The control software of the dynamometer is built using Labview software, which is used to measure the rollers speed through encoder and load through a load cell fitted with amplifier through a data acquisition of type NI- USB 6005 our built software controls the load of the eddy current dynamometer according to specified road resistances. Figure 3 shows control laptop and data acquisition and figure 4 shows the front panel of the control software.

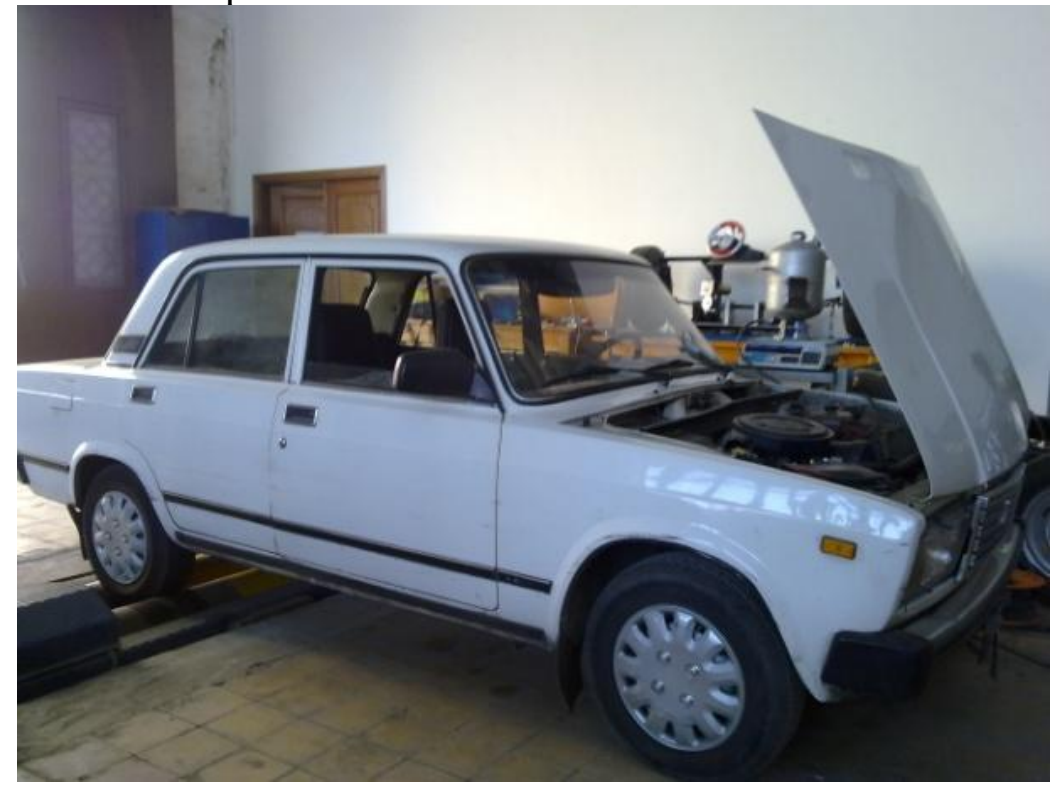

Fig. 2. Chassis Dynamometer

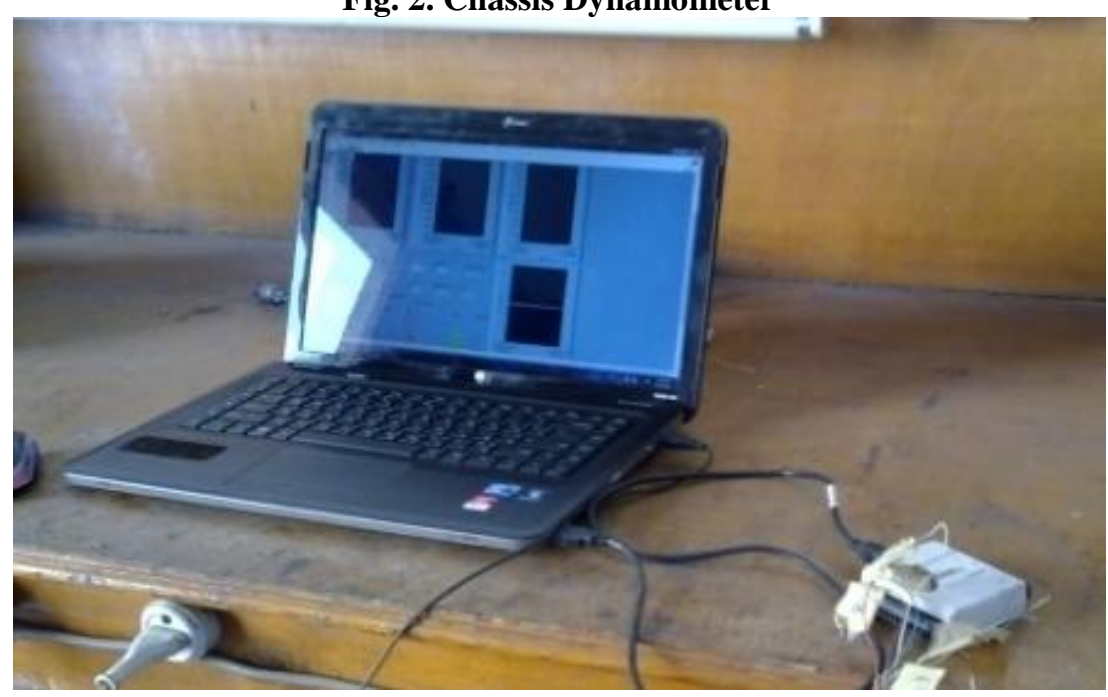

Fig. 3. Control Laptop and data acquisition 


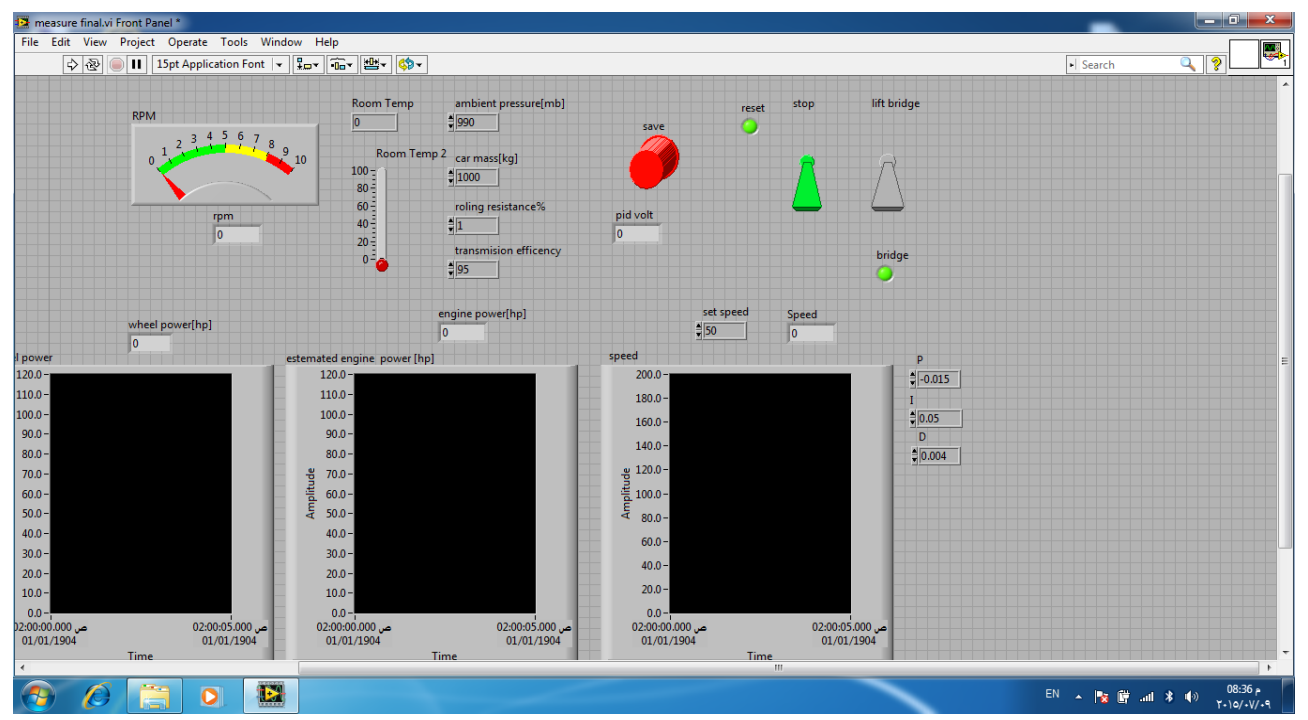

Fig.4. shows the front panel of the control software

2-The equipment used for road test are mainly three devices,

a) A high performance GPS of type Qstarz $818 \mathrm{XT}$ for reading the effective vehicle speed on road, shown in figure 5.

b) USB or bluetooth OBDII readers for reading engine speed and vehicle speed: Figure 6 shows USB OBDII reader.

c) Two smart phones for recording GPS and OBD data instantaneously and simultaneously.
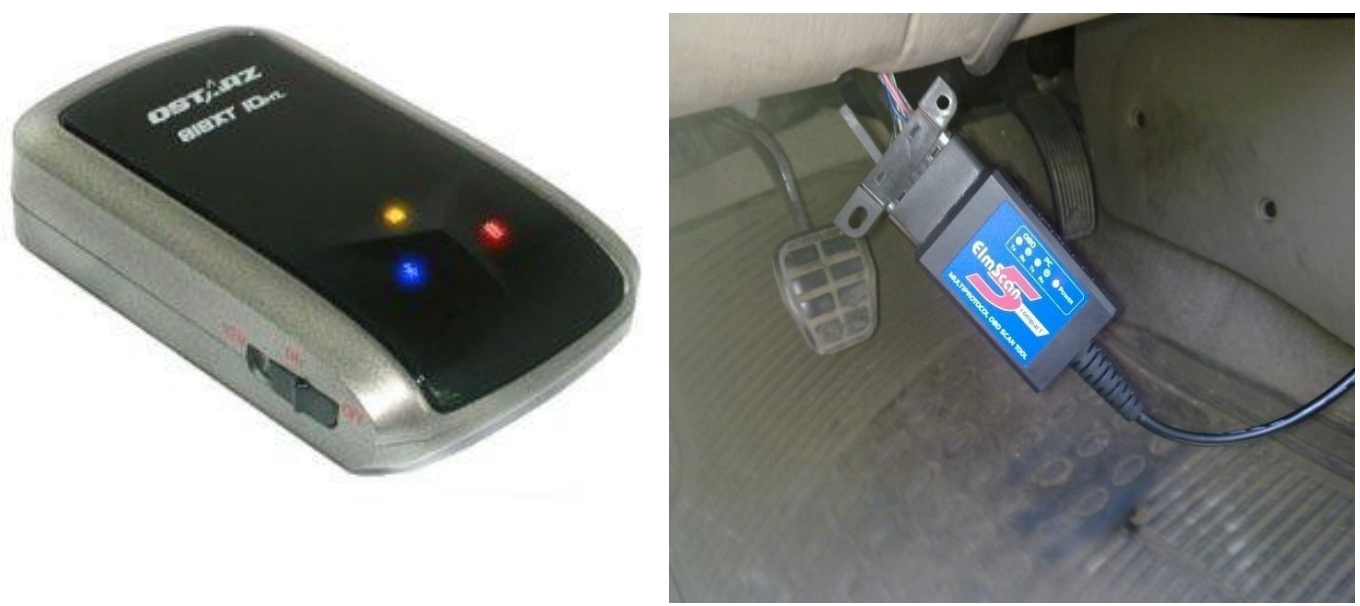

Fig. 5. Bluetooth Qstarz 818XT GPS Figure 6 USB OBDII Reader

\section{Procedure of experimental work}

Two sets of experiments is presented below:

1. Experiments on a chassis dynamometer where tests are performed in steady state conditions according to SAE J2264 1995 [10].

2. Experiments on road. The road tests are divided into two sets of tests the first is the coastdown test which is used to calculate the drag and rolling resistance coefficients of the vehicle. The second test is acceleration test; the vehicle is taken to level road, third gear engaged and starting from engine speed about 2000rpm, a full pressing on the accelerator pedal is applied. While the vehicle speed is recorded by the smart phone from the external GPS at a frequency $10 \mathrm{~Hz}$ and OBDII reader is used to read engine speed and vehicle speedometer speed and another smart phone till the engine speed reaches the maximum permissible engine speed ( in the tested vehicles about 6000 rpm). 
These tests have been repeated for three different passenger cars one of them without OBDII device (LADA 2107) where only GPS data is recorded in order to overcome error in speed measuring due to tires slip. The second vehicle (Hyundai Verna) is with manual transmission and OBDII and the third vehicle (Renault Logan) is with automatic transmission of type steptronic and OBDII. The data are then compiled using MS Excel. The compilation of the data includes filtration of noise using running average method and eliminating the wheel slip as the GPS measures the actual vehicle speed and OBDII is used to measure engine speed so eliminating the effect of clutch slip.

\section{RESULTS AND DISCUSSIONS}

The three vehicles are tested on road and on dynamometer then the results are compared beginning with a LADA 2107 that covered $20000 \mathrm{~km}$. The comparison between the road test and the dynamometer test is shown in figure 7. It is noted that there is a good agreement between the results of the two tests with error between the two power curves from $-1.5 \%$ to 4.5 $\%$ for the power curve and error between the two torque curves from $-0.7 \%$ to $3 \%$.

Second vehicle (Hyundai Verna) that covered $60000 \mathrm{~km}$ is tested using both GPS. The comparison between the road test with GPS and the dynamometer test is shown in figure 8. It is noted that there is a good agreement between the results obtained from the GPS and the dynamometer with error between the two power curves from $-3 \%$ to $5 \%$ for the power curve and error between the two torque curves from $-1.5 \%$ to $1.6 \%$.

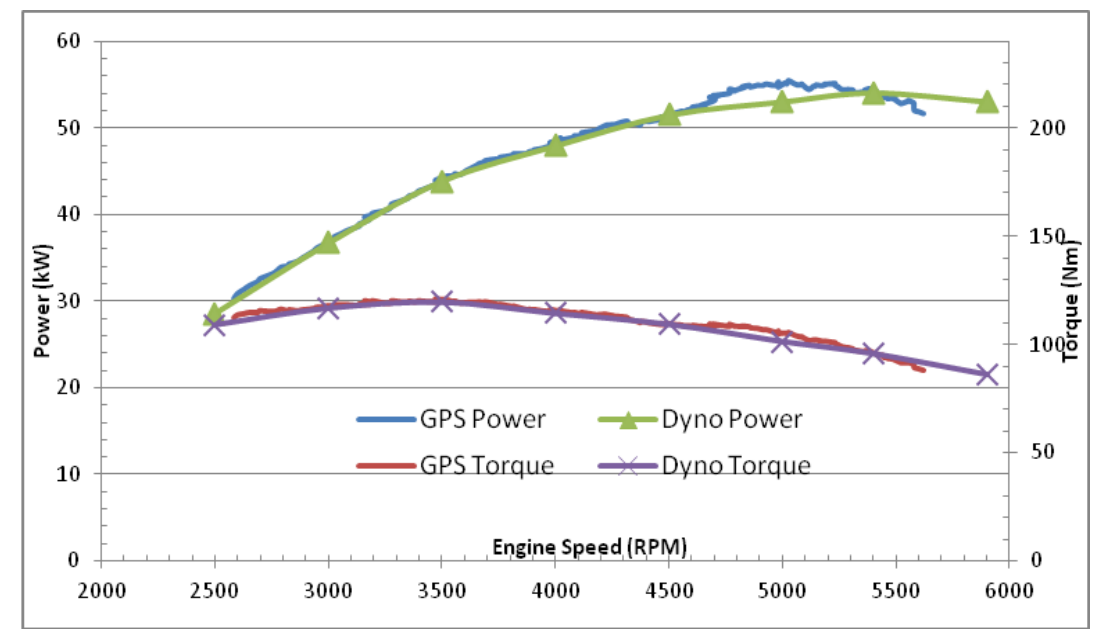

Fig. 7. Engine power and torque curves compared with road using GPS and Dynamometer tests for LADA 2107

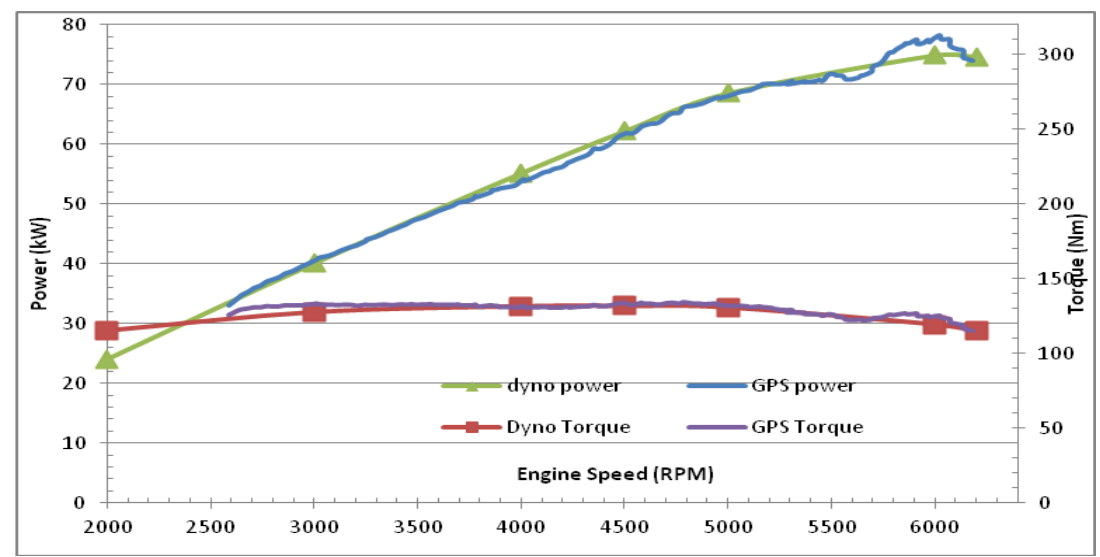

Fig. 8. Engine power and torque curves obtained using GPS versus Dynamometer tests for Hyundai Verna 
The comparison between the road test with GPS and OBDII with the dynamometer test is shown in figure 9. It is noted that there is a better agreement between the results obtained from the GPS and OBDII with the dynamometer with error between the two power curves from $-0.5 \%$ to $0.6 \%$, for the power curve and error between the two torque curves from $-0.5 \%$ to $0.7 \%$. It is noted that GPS and OBDII results is closer to dynamometer curves. This can be explained by that recording both engine speed and GPS actual vehicle speed overcome the slip in clutch and tires.

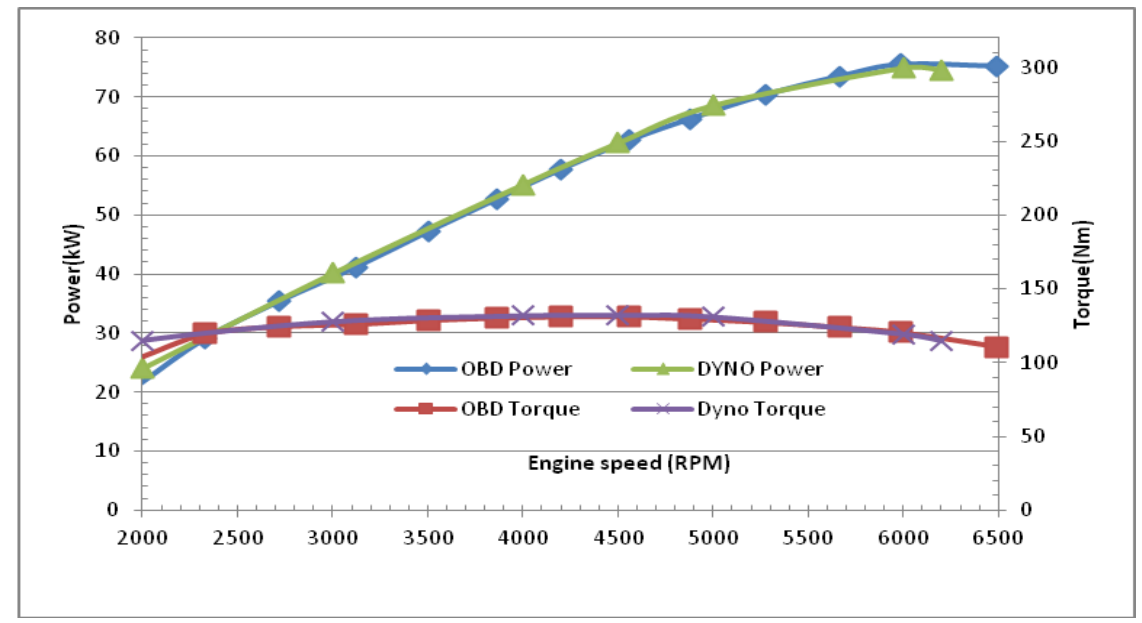

Fig. 9. Engine power and torque curves obtained from both GPS and OBD versus Dynamometer tests for Hyundai Verna

Third vehicle Renault Logan fitted with automatic transmission that covered $20000 \mathrm{~km}$ is tested using GPS with OBDII. The efficiency of torque converter is taken into account. The comparison between the road test with GPS and the dynamometer test is shown in figure 10 . It is noted that there is a good agreement between the results obtained from the GPS and the dynamometer with error between the two power curves from $-5 \%$ to $2 \%$ for the power curve and error between the two torque curves from $-1.5 \%$ to $1.6 \%$. The comparison between the road test with GPS with OBDII versus the dynamometer test is shown in figure 11. It is noted that there is a better agreement between the results obtained from the OBDII and the dynamometer with error between the two power curves from $-1.5 \%$ to $2 \%$ for the power curve and error between the two torque curves from $-1 \%$ to $1.5 \%$. It is noted that OBDII results and taking into account the slips (by using GPS) is closer to dynamometer results. The results are more accurate than the results produced by software products and are with good agreement with M. Pexa et al .

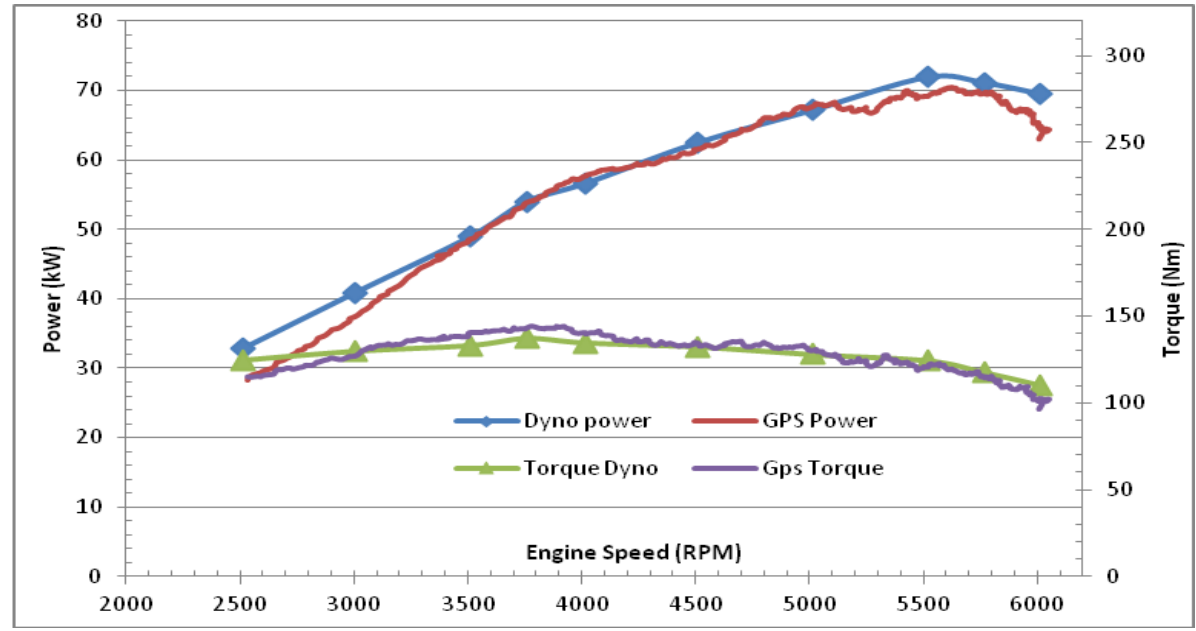

Fig. 10. Engine power and torque curves obtained from GPS versus Dynamometer tests for Renault Logan 


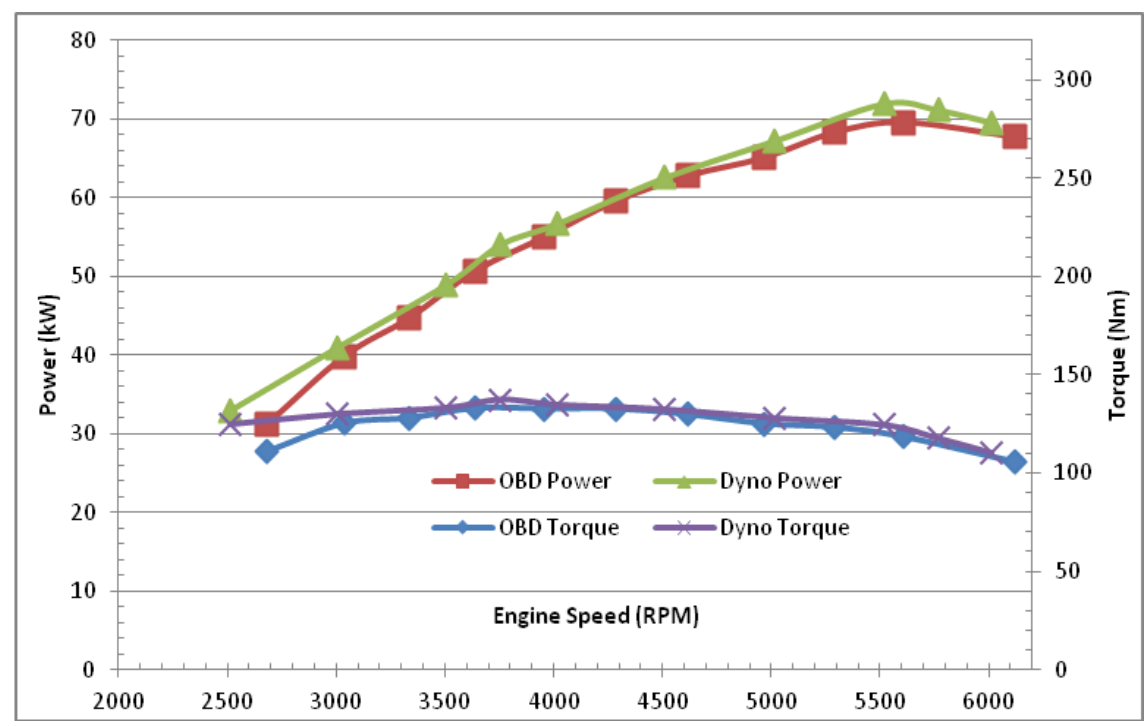

Fig. 11 Engine power and torque curves obtained from both GPS and OBD versus Dynamometer tests for Renault Logan

It should be noted here that the selection of the road is very important as the road should be level road and in a very good condition includes no bumps at all during testing as these bumps can lead to inaccurate results.

\section{CONCLUSIONS}

The road test using $10 \mathrm{~Hz}$ GPS and OBDII could be used as a method of estimating engine operating characteristics if drag and rolling resistance coefficients are measured according to SAE J2264 on level road. The road test using GPS is proved to measure engine power with an error varying from $\pm 5 \%$ and measure torque with an average error $\pm 3 \%$. The road test using GPS with OBDII is proved to measure engine power with an error varying from $\pm 2 \%$ and measure torque with an average error $\pm 1.5 \%$. This paper gives an economical method to inspect the engine power using road test, GPS and/or OBDII reader. This process can be used in workshops where there is no availability of dynamometer which give the workshop engineer a tool for inspecting automotive engine condition.

\section{REFERENCES}

1. J. Hromádko, J. Hromádko and B. Kadleček" Problems of power parameters measurement of constant speed engines with small cylinder volume by acceleration method" Eksploatacjai Niezawodność, 33: 19-22. 2007.

2. M. Pexa, M. Cindr and K. Kubín, V. Jurča "Measurements of tractor power parameters using GPS" Res. Agr. Eng. Vol. 57, 2011, No. 1: 1-7

3. http://www.palmerperformance.com/

4. SAE "Manual Transmission and Transaxle Efficiency and Parasitic Loss Measurement" SAE J2453 AUG1999.

5. Bosch "AUTOMOTIVE HANDBOOK" SAE ISDN 1-56091-918-3 $4^{\text {th }}$ Edition OCT 1996.

6. J.Y. Wong "Theory of Ground Vehicles" Third Edition JOHN WILEY AND SONS INC. 2001.

7. SAE "Engine Power Test Code-Spark Ignition And Compression IgnitionNet Power Rating" SAE J1349 1995-06.

8. H.B. Pacejka "Tire and Vehicle Dynamics" Pennsylvania, SAE International and Elsevier, 2005 .

9. http://www.racechrono.com/

10. SAE "Chassis Dynamometer Simulation Of Road Load Using Coastdown Techniques" SAE J2264 1995. 


\section{Nomenclatures and abbreviations}

$\mathrm{P}_{\text {wheels }}$

$\mathrm{P}_{\mathrm{e}}$

$\eta_{\text {trans }}$

$\eta_{\text {fr }}$

$\mathrm{F}_{\text {wheels }}$

Vivent

$\mathrm{F}_{\mathrm{ar}}$

$\mathrm{F}_{\mathrm{rr}}$

$\mathrm{F}_{\mathrm{gr}}$

$\mathrm{F}_{\mathrm{i}}$

$\mathrm{\rho}_{\mathrm{D}}$

$\mathrm{V}$

A

$\mathrm{F}_{\mathrm{Wr}}$

$\mathrm{H}$

$\mathrm{W}_{\mathrm{g}}$

$\theta$

$\mathrm{RE}$

$\gamma$

OBDII

GPS

NI wheels power

engine power

transmission efficiency

final reduction ratio efficiency

forces on wheels in the direction of motion

linear velocity of the vehicle

air resistance force

rolling resistance force

gradient resistance force

inertia force

air density

aerodynamic drag coefficient

vehicle speed

frontal area of the vehicle

rolling resistance coefficient

width of the vehicle without mirrors

height of the vehicle in

vehicle weight

road gradient

rotating parts effect

total reduction ratio

On Board Diagnostic System

improvement over OBD

Global Positioning System

National Instruments
$\mathrm{kW}$

$\mathrm{kW}$

$\mathrm{N}$

$\mathrm{m} / \mathrm{s}$

$\mathrm{N}$

$\mathrm{N}$

$\mathrm{N}$

$\mathrm{N}_{3}$

$\mathrm{m}^{3} / \mathrm{kg}$

$\mathrm{m}^{2} \mathrm{~s}$

$\mathrm{m}$

$\mathrm{m}$

$\mathrm{N}$

\section{Appendix A}

LADA 2107specifications

\begin{tabular}{|c|c|}
\hline & Engine \\
\hline $1569 \mathrm{cc}$ & Engine capacity \\
\hline 4-cylinder in-line 8-valve DOHC & Engine type \\
\hline 9.5 & Compression ratio \\
\hline \multirow[t]{2}{*}{$(79 \times 80.0) \mathrm{mm}$} & Bore $\mathrm{x}$ Stroke \\
\hline & Performance \\
\hline 55 kW @ 5600rpm & Power \\
\hline 120.0 Nm @ 3000rpm & Torque \\
\hline \multirow{2}{*}{$16 \mathrm{~s}(0-100 \mathrm{~km} / \mathrm{h})$} & Acceleration \\
\hline & Misc technical data \\
\hline 5-speed (M) & Transmission \\
\hline \multirow[t]{2}{*}{ Rear-wheel drive } & Drive type \\
\hline & Measurements \\
\hline Sedan & Vehicle type \\
\hline$(4145 \times 1620 \times 1446) \mathrm{mm}$ & Dimensions $(\mathrm{L} \times \mathrm{W} \times \mathrm{H})$ \\
\hline $2424 \mathrm{~mm}$ & Wheelbase \\
\hline $1,060 \mathrm{~kg}$ & Curb weight \\
\hline 175/70 R13 & Tire Size \\
\hline
\end{tabular}




\section{Appendix B}

Hyundai Verna specifications

\begin{tabular}{|c|c|}
\hline & Engine \\
\hline $1,599 \mathrm{cc}$ & Engine capacity \\
\hline 4-cylinder in-line 16-valve DOHC & Engine type \\
\hline 10 & Compression ratio \\
\hline \multirow[t]{2}{*}{$(76.5 \times 87.0) \mathrm{mm}$} & Bore x Stroke \\
\hline & Performance \\
\hline 78.2kW@5800rpm & Power \\
\hline 138 Nm@5000rpm & Torque \\
\hline \multirow[t]{2}{*}{$10.6 \mathrm{~s}(0-100 \mathrm{~km} / \mathrm{h})$} & Acceleration \\
\hline & Misc technical data \\
\hline 5-speed (Manual) & Transmission \\
\hline \multirow[t]{2}{*}{ Front-wheel drive } & Drive type \\
\hline & Measurements \\
\hline Sedan & Vehicle type \\
\hline$(4260 \times 1680 \times 1395) \mathrm{mm}$ & Dimensions $(\mathrm{L} \times \mathrm{W} \times \mathrm{H})$ \\
\hline $2440 \mathrm{~mm}$ & Wheelbase \\
\hline $1,110 \mathrm{~kg}$ & Curb weight \\
\hline $185 / 65$ R14 & Tire Size \\
\hline
\end{tabular}

\section{Appendix C}

Renault Logan1.6i 16V sedan specifications

\begin{tabular}{|c|c|}
\hline & Engine \\
\hline $1,598 \mathrm{cc}$ & Engine capacity \\
\hline 4-cylinder in-line 16-valve DOHC & Engine type \\
\hline 10 & Compression ratio \\
\hline \multirow[t]{2}{*}{$(79.5 \times 80.5) \mathrm{mm}$} & Bore $\mathrm{x}$ Stroke \\
\hline & Performance \\
\hline 78.2 kW@5750 rpm & Power \\
\hline 145Nm@3750 rpm & Torque \\
\hline \multirow{2}{*}{$11.9 \mathrm{~s}(0-100 \mathrm{~km} / \mathrm{h})$} & Acceleration \\
\hline & Misc technical data \\
\hline 4-speed (Automatic Steptronic) & Transmission \\
\hline \multirow[t]{2}{*}{ Front-wheel drive } & Drive type \\
\hline & Measurements \\
\hline Sedan & Vehicle type \\
\hline$(4250 \times 1735 \times 1525) \mathrm{mm}$ & Dimensions $(\mathrm{L} \times \mathrm{W} \times \mathrm{H})$ \\
\hline $2630 \mathrm{~mm}$ & Wheelbase \\
\hline $1,130 \mathrm{~kg}$ & Curb weight \\
\hline $185 / 65 \mathrm{R} 15$ & Tire Size \\
\hline
\end{tabular}

